Effect of Antiplatelet Therapy (Aspirin+Dipyridamole vs Clopidogrel) on Mortality Outcome in Ischemic Stroke

Raphae S. Barlas MPH, Yoon K. Loke MD, Mamas A. Mamas DPhil, Joao H Bettencourt-Silva PhD, Isobel Ford PhD , Allan B. Clark PhD , Kristian M. Bowles PhD , Anthony K. Metcalf MBChB , John F. Potter BMBS , Phyo K. Myint MD

PII: S0002-9149(18)31239-6

DOI: 10.1016/j.amjcard.2018.05.043

Reference: $\quad$ AJC 23352

To appear in: The American Journal of Cardiology

Received date: $\quad 6$ February 2018

Revised date: $\quad 23$ May 2018

Accepted date: 23 May 2018

Please cite this article as: Raphae S. Barlas MPH, Yoon K. Loke MD, Mamas A. Mamas DPhil, Joao H Bettencourt-Silva PhD, Isobel Ford PhD, Allan B. Clark PhD, Kristian M. Bowles PhD , Anthony K. Metcalf MBChB , John F. Potter BMBS, Phyo K. Myint MD , Effect of Antiplatelet Therapy (Aspirin+Dipyridamole vs Clopidogrel) on Mortality Outcome in Ischemic Stroke, The American Journal of Cardiology (2018), doi: 10.1016/j.amjcard.2018.05.043

This is a PDF file of an unedited manuscript that has been accepted for publication. As a service to our customers we are providing this early version of the manuscript. The manuscript will undergo copyediting, typesetting, and review of the resulting proof before it is published in its final form. Please note that during the production process errors may be discovered which could affect the content, and all legal disclaimers that apply to the journal pertain. 


\section{Effect of Antiplatelet Therapy (Aspirin + Dipyridamole vs Clopidogrel) on Mortality Outcome in Ischemic Stroke}

Running title: Discharge antiplatelet affects ischemic stroke mortality

Raphae S. Barlas MPH ${ }^{\mathrm{a}}$, Yoon K. Loke MD ${ }^{\mathrm{b}}$, Mamas A. Mamas DPhil ${ }^{\mathrm{c}}$, Joao H Bettencourt-Silva $\mathrm{PhD}^{\mathrm{d}}$, Isobel Ford $\mathrm{PhD}^{\mathrm{a}}$, Allan B. Clark $\mathrm{PhD}^{\mathrm{d}}$, Kristian M. Bowles $\mathrm{PhD}^{\mathrm{e}}$, Anthony K. Metcalf $\mathrm{MBChB}^{\mathrm{e}}$, John F. Potter BMBS ${ }^{\mathrm{e}}$, Phyo K. Myint MD ${ }^{\mathrm{a}}$

a Institute of Applied Health Sciences, Aberdeen, UK.

b Stroke Research Group, Norfolk and Norwich University Hospital, Norwich, UK.

c Keele Cardiovascular Research Group, Keele University, Stoke-on-Trent and Academic Department of Cardiology, Royal Stroke Hospital, Stroke on Trent.

d Norwich Medical School, University of East Anglia, Norwich, UK.

e Stroke Research Group, Norfolk and Norwich University Hospital, Norwich, UK.

\section{Correspondence to:}

Mr. Raphae S Barlas

Ageing Clinical and Experimental Research

Institute of Applied Health Sciences, School of Medicine \& Dentistry,

University of Aberdeen,

Foresterhill, Aberdeen, AB25 2ZD, United Kingdom

Tel: +44 (0) 1224437974

Fax: +44 (0) 1224437971

E-mail: raphae.barlas.13@aberdeen.ac.uk 


\section{Abstract}

The optimal regimen of antiplatelet therapy for secondary prevention in noncardioembolic ischemic stroke remains controversial. We aimed to determine which regimen was associated with the greatest reduction in adverse outcomes. We analysed prospectively collected data from the Norfolk and Norwich University Hospital Stroke Register (NNUHSR). The sample population consisted of 3,572 participants (mean age $74.96 \pm 12.67$ ) with ischemic stroke, who were consecutively admitted between 2003-2015. Patients were placed on one of three antiplatelet regimens at hospital discharge; aspirin monotherapy, aspirin plus dipyridamole and clopidogrel. Clopidogrel and aspirin plus dipyridamole was compared to aspirin. A direct comparison between clopidogrel and aspirin plus dipyridamole was also performed. Outcomes included all-cause mortality and a combined endpoint of all-cause mortality and incidence of major adverse cardiac events (stroke or myocardial infarction). Cox-regression models adjusted for potential confounders at the following time periods after discharge; 0-90 days, 91-365 days and 1-3 years. Aspirin plus dipyridamole was associated with a lower risk of mortality at 0-90 days; HR 0.62 (0.43-0.91). Clopidogrel was associated with a lower risk of mortality at 1-3 years; HR of 0.39 (0.26-0.60). Similar HRs were observed for the the corresponding time points in the composite outcome. In conclusion Patients with noncardioembolic stroke may gain maximum benefit from aspirin plus dipyridamole initially ( $\leq 1$ year) with a subsequent switch to clopidogrel, with regard to mortality and MACE outcomes.

Key Words: Ischemic stroke, secondary prevention, antiplatelets, outcomes 


\section{Introduction}

Antiplatelet agents form the cornerstone of secondary preventative therapy in patients with noncardioembolic ischemic stroke. A recent meta-analysis of clinical trials found the combination of aspirin plus dipyridamole to be more effective than aspirin monotherapy in reducing the risk of stroke and other serious vascular events [1]. The CAPRIE trial found that clopidogrel reduced the risk of a combined end-point of ischemic stroke, myocardial infarction or vascular death in patients at risk of ischemic events, compared to aspirin. However, this relationship was only statistically significant in patients with peripheral vascular disease, not within the ischemic stroke sub-group of patients [2]. The PRoFESS trial directly compared clopidogrel with aspirin plus dipyridamole and found that both regimens had similar efficacy [3]. National guidelines have made different recommendations with regards to the optimal antiplatelet for preventative therapy [4-6]. Due to the regarding the optimal antiplatelet therapy for secondary prevention in ischemic stroke, the current study aimed to evaluate which antiplatelet therapy had the greatest short and long term efficacy.

\section{Methods}

We retrospectively analysed data from a study population consisting of 3,575 patients with ischemic stroke who were admitted consecutively to the Norfolk and Norwich University Hospital (NNUH) between January 2003 and May 2015. NNUH is a tertiary regional care centre with a catchment population of $\sim 750,000$. The methods of data collection used in the NNUH stroke register have been reported previously [7]. In brief, data from paper and electronic records were prospectively entered into the database by clinical team members. Follow-up mortality status, recurrent stroke (ICD10: I63) and myocardial infarction (ICD10-I I21) were ascertained by electronic record linkage with the Office of National Statistics. We therefore have almost $100 \%$ follow up (see Supplementary Figure 1). Only confirmed cases of ischemic stroke, diagnosed using a combination of clinical features and imaging (CT or MRI), were included. Ethical approval was obtained from the Newcastle and Tyneside National Health Service (NHS) Research Ethics Committee (12/NE/0170) and the study protocol was approved by the Steering Committee of the 
Register. The study therefore conformed to the ethical guidelines of the 1975 Declaration of

Helsinki. As this was a registry based study, consent was not gained from each individual patient.

Patients diagnosed with atrial fibrillation (AF) prior to stroke and during the follow-up period were excluded in an attempt to remove potential cardioembolic strokes. Furthermore, this mitigated the confounding effect of switching from antiplatelet at discharge to anticoagulation at a later date (usually 8-12 weeks after ictus). Patients on all other antiplatelet regimens or on any type of anticoagulant for other purposes at the time of discharge were also excluded. Patients who died as inpatients were not included in order to focus on the relationship between discharge antiplatelet and long-term outcomes. Study follow-up therefore begins from the point of hospital discharge with discharge antiplatelet therapy as the predictor variable. Patients receiving aspirin and clopidogrel both received dosages of $75 \mathrm{mg}$ once daily. Patients receiving aspirin + dipyridamole where given a combined extended release variant which contained $25 \mathrm{mg}$ of aspirin and $200 \mathrm{mg}$ of dipyridamole.

The variables included in the study were age, sex, pre-stroke disability depicted by modified Rankin score $(0-5)$, Oxfordshire Community Stroke Project (OCSP) classification (Total Anterior Circulation Infarction, Partial Anterior Circulation Infarction, Posterior Circulation Infarction, Lacunar Infarction), prior antiplatelet use (yes/no) and co-morbidities (Previous Stroke/Transient Ischemic Attack, Coronary Heart Disease/Myocardial Infarction, Congestive Heart Failure, Hypertension, Hyperlipidemia, Diabetes Mellitus, Peripheral Vascular Disease, Chronic Obstructive Pulmonary Disease, Chronic Kidney Disease, Falls, Malignancy, Dementia). The outcomes of interest were (1) all-cause mortality and (2) a combined end-point of all-cause mortality and major adverse cardiac eyents defined as either incident stroke or myocardial infarction (mortality \& MACE). For the latter outcome, the event was censored at the occurrence of whichever occurred first out of stroke, myocardial infarction or death. Outcomes were assessed at the following timeperiods; 0 - 90 days, 91 - 365 days and 366 - 1095 days (' 1 - 3 years’). These time points were chosen in order to assess both short and long term outcomes in a manner that preserved a sufficient level of statistical power. 
The associations between choice of antiplatelet regimen with age, sex, pre-stroke modified

Rankin score, OCSP Classification, prior-antiplatelet use and co-morbidities were assessed using the chi-square test. Cox proportional hazard models were constructed in order to evaluate the impact of different antiplatelet therapies on stroke outcomes. Unadjusted and adjusted hazard ratios were obtained from univariate and multivariate models. Survival analysis was performed controlling for age, sex, pre-stroke modified Rankin score, OCSP classification, prior-antiplatelet use, co-morbidities and year of hospital discharge. Statistical analysis was performed using SPSS version 24.0 (SPSS Inc., Chicago, Illinois, USA).

\section{Results}

The cohort consisted of 3,575 patients with ischemic stroke. The mean age (SD) was 74.96 $( \pm 12.67)$ years and $50.7 \%$ were male and the most common stroke subtype was Partial Anterior Circulation Stroke (37.3\%). Antiplatelet therapy at discharge included 953 (26.7\%) patients on aspirin, 1,067 (29.8\%) on aspirin plus dipyridamole combination and 1,555 (43.5\%) on clopidogrel. Mean values for person-years of treatment for aspirin monotherapy, aspirin plus dipyridamole and clopidogrel were $2.36,2.51$ and 2.66 respectively. During follow-up there were a total of 840 events (deaths) for the mortality outcome and 911 events in the composite outcome (732 deaths, 126 stroke, $53 \mathrm{MI})$. The apparent discrepancy in mortality frequency between the two outcomes is due to the censoring of patients once they experience stroke, MI or mortality in the composite outcome. As a result, some patients were censored prior to experiencing mortality, thereby making the frequency of mortality appear lower in the combined outcome.

Table 1 shows sample characteristics by antiplatelet therapy at discharge. Descriptive comparison statistics were made using aspirin as the reference point. Aspirin use was associated with older age, female sex, higher pre-stroke disability, less severe form of stroke (Lacunar Infarction) and no prior antiplatelet use before the index stroke. Clopidogrel use was associated with increased prevalence of a number of comorbid conditions including; Coronary Heart Disease/Myocardial Infarction, Hypertension, Hyperlipidemia, Diabetes Mellitus, Peripheral 
Vascular Disease, Chronic Obstructive Pulmonary Disease and Chronic Kidney Disease.

Aspirin/dipyridamole dual antiplatelet therapy was also associated with increased prevalence of a number of comorbidities, albeit to a lesser extent than clopidogrel monotherapy. These included Previous Stroke/Transient Ischaemic Attack, Coronary Heart Disease/Myocardial Infarction, Hypertension and Hyperlipidemia. Unadjusted Kaplan-Meier survival curves for patients receiving different antiplatelet therapies are depicted in Figure 1. Visual inspection of the curves suggested that both clopidogrel and aspirin plus dipyridamole are associated with better outcomes at $\sim 2$ months compared to aspirin alone, after which the effectiveness of clopidogrel surpasses that of aspirin plus dipyridamole.

Table 2 shows the risk of mortality and mortality + MACE according to antiplatelet therapy at various time intervals ( 0 - 90 days, $91-365$ days, $1-3$ years). After adjusting for potential confounders, we found that aspirin plus dipyridamole dual antiplatelet therapy was associated with a lower risk of mortality and mortality + MACE at $0-90$ days compared to aspirin. Clopidogrel was associated with reduced risk of mortality and mortality + MACE at $1-3$ years. Table 3 depicts adjusted hazard ratios of mortality and mortality + MACE for clopidogrel compared to aspirin plus dipyridamole. Clopidogrel had significantly better outcomes in the long term ( $1-3$ years) and aspirin plus dipyridamole had significantly better outcomes in the short term ( 0 - 90 days).

Supplementary Table 1 depicts crude rates of mortality, myocardial infarction and stroke according to discharge antiplatelet therapy. Aspirin had the highest rates of all three events whereas clopidogrel had the lowest.

\section{Discussion}

The current study found aspirin plus dipyridamole to be associated with better short term outcomes then aspirin monotherapy, with a $38 \%$ relative risk reduction in mortality $0-90$ days after discharge. In contrast, clopidogrel use was associated with better longer term outcomes when compared to aspirin; with a $61 \%$ relative risk reduction in mortality at $1-3$ years after discharge. When comparing clopidogrel to aspirin plus dipyridamole directly, clopidogrel was significantly 
associated with better mortality outcomes in the long term ( $1-3$ years), whereas aspiring plus dipyridamole was significantly better in the short term ( 0 - 90 days $)$.

The CAPRIE trial evaluated the effectiveness of clopidogrel compared to aspirin [2] as preventative therapy in patients at risk of ischemic events. This trial demonstrated that patients with clopidogrel had a relative risk (RR) reduction of $7.3 \%$, however, this was not statistically significant $(\mathrm{p}=0.26)$. Due to an observational design, the current study cannot be directly compared to the CAPRIE trial. The difference between our findings and those in the CAPRIE trial may be explained by the difference in means follow-up times; CAPRIE trial $=1.91$ years and current study $=1.91$ years [8]. It is possible that by including all consecutively admitted strokes within the Norfolk region of the UK in combination with a long-term follow-up, our study captured the statistically significant improvements in outcome for clopidogrel, which oceurred after 1-year post discharge. The observed long-term benefit of clopidogrel within the current study may be due to the reduced occurrence of recurrent stroke when compared to aspirin and aspirin plus dipyridamole (see crude rates of MACE in Supplementary Table 1). Furthermore, a meta-analysis has found clopidogrel to be associated with fewer bleeding complications when compared to aspirin as preventative therapy in cardiovascular disease [9]. While the appropriate data was not available in the current study, it is possible that clopidogrel led to better outcomes when compared to aspirin due to a reduced rate of bleeding complications.

Six randomised controlled trials have compared the effectiveness of aspirin plus dipyridamole to aspirin monotherapy in improving outcomes in non-cardioembolic ischemic stroke [10 - 15]. A meta-analysis found aspirin plus extended release dipyridamole to be associated with a significant reduction in the RR of the composite endpoint of nonfatal stroke, nonfatal MI and vascular death; $0.82(0.73-0.92)[16]$. Patients in the current study who received aspirin and dipyridamole were given extended release dipyridamole. Interestingly, the current study observed favourable outcomes for aspirin and dipyridamole compared to aspirin monotherapy and clopidogrel in the short-term only. As an observational study we were unable to take into account the potential confounding effect of adherence associated with dipyridamole use. In the ESPS2 trial 
(investigating the efficacy of aspirin/dipyridamole as secondary preventative therapy for ischemic stroke) $8 \%$ of patients on aspirin/dipyridamole had to withdraw due to headache [17]. For this reason, it is possible that poor adherence secondary to side effects accounts for the absence of any observed long-term benefit of aspirin plus dipyridamole over aspirin monotherapy in the current study.

Newer antiplatelets such as ticagrelor are now used in patients with acute coronary syndromes [18], however, a recent trial has found that ticagrelor is non-superior to aspirin monotherapy for secondary prevention in non-cardioembolic stroke [19]. Similarly, dualantiplatelet therapy is routinely used in acute coronary syndromes, however, guidelines have recommended against the use of aspirin + clopidogrel for secondary prevention in stroke due to increased bleeding risk [4-6]. A recent meta-analysis of randomised trials analyzed the short term efficacy ( $\leq 1$ year) of dual antiplatelet therapy (aspirin + clopidogrel and aspirin + dipyridamole) compared to monotherapy, for secondary prevention in non-cardioembolic ischemic stroke [20], found that both types of dual therapy were significantly associated with improved short term outcomes when compared to monotherapy, without a concomitant increase in adverse outcomes. These findings suggest that increased rates of bleeding events are more likely when dual antiplatelet therapy is used in the long term only. Patients with non-cardioembolic ischemic stroke may therefore benefit from initially receiving dual therapy such as aspirin plus dipyridamole, with a switch to monotherapy within 12 months, in a manner similar to patients with acute coronary syndromes [21]

This study had a number of limitations. Firstly, clinical factors may have informed the decision to prescribe a particular antiplatelet regimen to patients within the study. Furthermore, patients prescribed aspirin were concentrated in the years before 2011, whereas those prescribed clopidogrel were concentrated in the years after 2011 (Supplementary Figure 2). We have attempted to account for these potential sources of bias by adjusting for year of treatment in our multivariate analysis. We were also able to control for age, sex, pre-stroke disability, stroke severity and prognosis through OCSP classification, prior antiplatelet use and wide range of chronic co- 
morbidities which are important for both short and long term outcomes. Studies have shown premorbid Rankin score [22] and OCSP classification [23] to be major determinants of mortality in stroke patients beyond short term mortality. However, as an observational study, we were unable to definitively account for confounding by indication and residual confounding. While we have attempted to exclude patients with cardioembolic stroke by excluding patients with AF, there is the possibility of some misclassification. While the current study was conducted on a population from a single center, thereby limiting the generalizability of our findings, the NNUH register captured all admissions for stroke within the Norfolk region of the United Kingdom and participants were identified prospectively with near complete follow-up was through data linkage to Office of National Statistics in the UK, to ascertain events. This method has been shown to have high validity [24]. In addition, we did not have data on compliance with medication, or control for changes in medication made in primary care after hospital discharge. Data specifying the cause of mortality were not available, meaning that we were unable to determine whether mortality was related to vascular pathology or other co-morbidities. Finally, data on bleeding outcomes was not available, which entailed that we were unable to assess this outcome.

In summary, this study has demonstrated an association between aspirin plus dipyridamole dual therapy with better short-term outcomes and clopidogrel with better long-term outcomes when compared to aspirin monotherapy. Our findings therefore suggest that ischemic stroke patients may benefit from dual aspirin plus dipyridamole therapy initially $(\leq 1$ year) with a subsequent switch to clopidogrel therapy. Future studies evaluating the long-term impact of aspirin plus dipyridamole and clopidogrel should focus on additional outcomes such as bleeding risk and vascular death. 
Funding Sources: RSB received Vacation Scholarship Grant from the Medical Research Scotland (Grant number: VAC-847-2015) to conduct the research. The NNUH Stroke and TIA Register is maintained by the NNUH NHS Foundation Trust Stroke Services. The funders have no role in study design, analysis plan and interpretation and reporting of the study results.

Declaration of interest: None. 


\section{Bibliography}

1. Verro P, Gorelick PB, Nguyen D. Aspirin plus dipyridamole versus aspirin for prevention of vascular events after stroke or TIA: a meta-analysis. Stroke 2008;39:1358-1363.

2. CAPRIE Steering Committee. A randomised, blinded, trial of clopidogrel versus aspirin in patients at risk of ischemic events (CAPRIE). Lancet 1996;348:1329-1339.

3. Sacco RL, Diener HC, Yusuf S, Cotton D, Ounpuu S, Lawton WA. Aspirin and ExtendedRelease Dipyridamole versus Clopidogrel for Recurrent Stroke. N Engl J Med 2008;359:1238-1251.

4. National Institute for Health and Care Excellence (NICE). Clopidogrel and modified-release dipyridamole for the prevention of occlusive vascular events. London: NICE; 2014.

5. Kernan WN, Ovbiagele B, Black HR, Bravata DM, Chimowitz MI, Ezekowitz MD. Guidelines for the Prevention of Stroke in Patients with Stroke and Transient Ischemic Attack [published online May 1, 2014]. Stroke doi:10.1161/STR.000000000000000024.

6. European Stroke Organization (ESO). Guidelines for Management of Ischaemic Storke and Transient Ischaemic Attack Heidelberg: ESO; 2008.

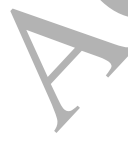

7. Bettencourt-Silva J, De La Iglesia B, Donnel S, Rayward-Smith V. On creating a patient-centric database from multiple Hospital Information Systems. Methods Inf Med 2012;51:210-220. 
8. Lee M, Wu Y, Saver J, Lee HC, Lee JD, Chang KC, Wu CY, Lee TH, Wang HH, Rao NM,

Ovbiagele B. Is clopidogrel better than aspirin following breakthrough strokes while on aspirin? A retrospective cohort study. BMJ Open 2014:4:e006672 doi:10.1136/bmjopen-2014-006672.

9. McQuaid KR, Laine L. Systematic review and meta-analysis of adverse events of low-dose aspirin and clopidogrel in randomized controlled trials. Am J Med 2006;119:624-638.

10. Caneschi S, Bonaventi C, Finzi F. Ischemic cerebrovascular disease: treatment with various anti-platelet aggregation drugs. Clinical follow-up of 80 patients (22-34 months). Minerva Med 1985;76:1933-1943.

11. Guiraud-Chaumeil B, Rascol A, David J, Boneu B, Clanet M, Bierme R. Pre'vention des re'cidives des accidents vasculaires ce're braux ische miques par les anti-agre'gants plaquettaires: resultants d'un essai the'rapique controle' de 3 ans. Rev Neurol 1982;138:367-385.

12. Bousser MG, Eschwege E, Haguenau M, Lefaucconnier JM, Thibult N, Touboul D, Touboul PJ. "AICLA" controlled trial of aspirin and dipyridamole in the secondary prevention of atherothrombotic cerebral ischemia. Stroke 1983;14:5-14.

13. American-Canadian Cooperative Study Group. Persantine aspirin trial in cerebral ischemia, part II: endpoint results. Stroke 1985;16:406-415.

14. Diener H-C, Cunha L, Forbes C, Sivenius J, Smets P, Lowenthal A. European Stroke Prevention Study 2: dipyridamole and acetylsalicylic acid in the secondary prevention of stroke. $J$ Neurol Sci 1996;143:1-13. 
15. Halkes PH, Van Gijn J, Kappelle LJ, Koudstaal PJ, Algra A. Aspirin plus dipyridamole versus aspirin alone after cerebral ischaemia of arterial origin (ESPRIT): randomised controlled trial. Lancet 2006;367:1665-1673.

16. Verro P, Gorelick P, Nguyen D. Aspirin plus dipyridamole versus aspirin for prevention of vascular events after stroke or TIA. Stroke 1008;39:1358-1363.

17. Diener HC, Sacco RL, Yusuf S, Cotton D, Ounpuu S, Lawton WA, Palesch Y, Martin RH, Albers GW, Bath P, Bornstein N, Chan BP, Chen ST, Cunha L, Dahlof B, De Keyser J, Donnan GA, Estol C, Gorelick P, Gu V, Hermansson K, Hilbrich L, Kaste M, Lu C, Măchnig T, Pais P, Roberts R, Skvortsova V, Teal P, Toni D, VanderMaelen C, Voigt T, Weber M, Yoon BW. Effects of aspirin plus extended-release dipyridamole versus clopidogrel and telmisartan on disability and cognitive function after recurrent stroke in patients with ischemic stroke in the Prevention Regimen for Effectively Avoiding Second Stroke (PRoFESS) trial: a double-blind, active and placebocontrolled study. Lancet Neurol 2008:7;875-884.

18. Amsterdam EA, Wenger NK, Brindis RG, Casey DE Jr, Ganiats TG, Holmes DR Jr, Jaffe AS, Jneid H, Kelly RF, Konton MC, Levine GN, Liebson PR, Mukherjee D, Peterson E, Sabatine MS, Smalling RW, Zieman SJ. 2014 AHA.ACC Guideline for the Management of Patients with NonST-Elevation Acute Coronary Syndromes: a report of the American College of

Cardiology/American Heart Association Task Force on Practice Guidelines. J Am Coll Cardiol 2014:64:e139-e228.

19. Johnston SC, Amarenco P, Albers GW, Denison H, Easton JD, Evans SR, Held P, Jonasson J, Minematsu K, Molina CA, Wang Y, Wong KS; SOCRATES Steering Committee and Investigators. Ticagrelor versus Aspirin in Acute Stroke or Transient Ischemic Attack. N Engl J Med 2016:7;35-43. 
20. Liu Y, Fei Z, Wang W, Fang J, Meijuan Z, Cheng G. Efficacy and safety of short-term dualversus mono-antiplatelet therapy in patients with ischemic stroke or TIA: a meta-analysis of 10 randomized controlled trials. J Neurol 2016:263:2247-2259.

21. Wilson, SJ, Newby D, Dawson D, Irving J, Berry C. Duration of dual antiplatelet therapy in acute coronary syndrome. Heart 2017;103:573-580.

22. Kwok CS, Clark A, Ford GA, Durairaj R, Dixit AK, Davis J, Sharma AK, Potter JF, Myint PK. Association between prestrike disability and inpatient mortality and length of acute hospital stay after acute stroke. J Am Geriatr Soc 2012;60:726-732

23. Bamford J, Sandercock P, Dennis M, Warlow C, Burn J. Classification and natural history of clinically identifiable subtypes of cerebral infarction. The Lancet 1991:337:1521-1526

24. Sinha S, Myint PK, Luben RN, Khaw KT. Accuracy of death certification and hospital record linkage for identification of incident stroke. BMC Med Res Methodol 2008;8:74 


\section{Figure Legend:}
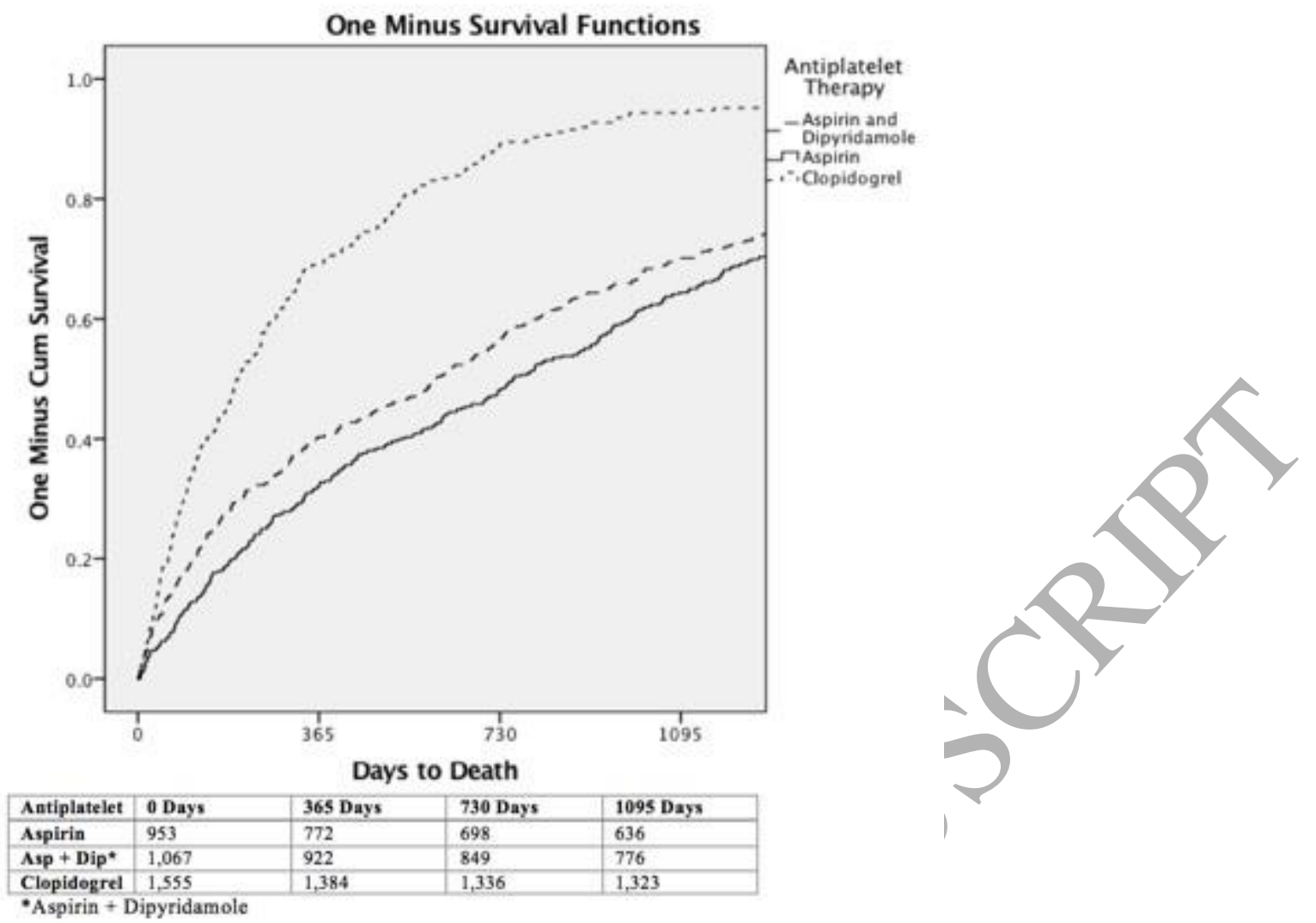

Figure 1: Kaplan-Meier Survival Curve of Mortality Outcome by Antiplatelet Therapy 
Table 1: Sample Characteristics by Discharge Antiplatelet Therapy

\begin{tabular}{|c|c|c|c|c|c|c|}
\hline Variable & Aspirin & $\begin{array}{c}\text { Aspirin and } \\
\text { Dipyridamole }\end{array}$ & $\begin{array}{c}\mathrm{P}- \\
\text { Value }\end{array}$ & Clopidogrel & $\begin{array}{c}\text { P- } \\
\text { Value }\end{array}$ & Total \\
\hline & $\begin{array}{l}(\mathrm{n}= \\
953)\end{array}$ & $(\mathrm{n}=1,067)$ & \multirow{10}{*}{$<0.001$} & $(\mathrm{n}=1,555)$ & \multirow{10}{*}{0.001} & $\begin{array}{c}(\mathrm{n}= \\
3,575)\end{array}$ \\
\hline \multicolumn{5}{|l|}{ Age } & & \\
\hline$\leq 60$ & $\begin{array}{c}161 \\
(16.9 \\
\%)\end{array}$ & $98(9.2 \%)$ & & $\begin{array}{c}223(14.3 \\
\%)\end{array}$ & & $\begin{array}{c}482 \\
(13.5 \\
\%)\end{array}$ \\
\hline $61-65$ & $\begin{array}{c}54(5.7 \\
\%)\end{array}$ & $96(9.0 \%)$ & & $145(9.3 \%)$ & & $\begin{array}{l}295 \\
83\end{array}$ \\
\hline $66-70$ & $\begin{array}{c}81(8.5 \\
\%)\end{array}$ & $104(9.7 \%)$ & & $\begin{array}{c}171(11.0 \\
\%)\end{array}$ & & \\
\hline $71-75$ & $\begin{array}{c}123 \\
(12.9 \\
\%)\end{array}$ & $147(13.8 \%)$ & & $\begin{array}{c}212(13,6 \\
\%)\end{array}$ & & $\begin{array}{c}482 \\
(13.5 \\
\%)\end{array}$ \\
\hline $76-80$ & $\begin{array}{c}134 \\
(14.1 \\
\%)\end{array}$ & $205(19.2 \%)$ & & $241(15.5$ & & $\begin{array}{c}580 \\
(16.2 \\
\%)\end{array}$ \\
\hline $81-85$ & $\begin{array}{c}166 \\
(17.4 \\
\%)\end{array}$ & $214(20.1 \%)$ & & $\begin{array}{c}259(16.7 \\
\%)\end{array}$ & & $\begin{array}{c}639 \\
(17.9 \\
\%)\end{array}$ \\
\hline $86-90$ & $\begin{array}{c}145 \\
(15.2 \\
\%)\end{array}$ & $143(13.4 \%)$ & & $\begin{array}{c}194(12.5 \\
\%)\end{array}$ & & $\begin{array}{c}482 \\
(13.5 \\
\%)\end{array}$ \\
\hline$\geq 91$ & $\begin{array}{c}89(9.3 \\
\%)\end{array}$ & $60(5.6 \%)$ & & $110(7.1 \%)$ & & $\begin{array}{l}259 \\
(7.2 \\
\%)\end{array}$ \\
\hline Men & $\begin{array}{c}453 \\
(47.5 \\
\%)\end{array}$ & $564(52.9 \%)$ & 0.017 & $\begin{array}{c}797(51.3 \\
\%)\end{array}$ & 0.071 & $\begin{array}{c}1,814 \\
(50.7 \\
\%)\end{array}$ \\
\hline Women & $\begin{array}{c}500 \\
(52.5 \\
\%)\end{array}$ & $503(47.1 \%)$ & & $\begin{array}{c}758(48.7 \\
\%)\end{array}$ & & $\begin{array}{c}1,761 \\
(49.3 \\
\%)\end{array}$ \\
\hline Pre-stroke mRS & & & & & & \\
\hline 0 & $\begin{array}{c}648 \\
(68.0 \\
\%)\end{array}$ & $750(70.3 \%)$ & 0.003 & $\begin{array}{c}1070(68.8 \\
\%)\end{array}$ & $<0.001$ & $\begin{array}{c}2,468 \\
(69.0 \\
\%)\end{array}$ \\
\hline & $\begin{array}{c}79(8.3 \\
\%)\end{array}$ & $106(9.9 \%)$ & & $\begin{array}{c}228(14.7 \\
\%)\end{array}$ & & $\begin{array}{c}413 \\
(11.6 \\
\%)\end{array}$ \\
\hline 2 & $\begin{array}{c}67(7.0 \\
\%)\end{array}$ & $89(8.3 \%)$ & & $102(6.6 \%)$ & & $\begin{array}{l}258 \\
(7.2 \\
\%)\end{array}$ \\
\hline 3 & $\begin{array}{c}91(9.5 \\
\%)\end{array}$ & $85(8.0 \%)$ & & $101(6.5 \%)$ & & $\begin{array}{c}277 \\
(7.7 \\
\%)\end{array}$ \\
\hline 4 & $\begin{array}{c}56(5.9 \\
\%)\end{array}$ & $29(2.7 \%)$ & & $40(2.6 \%)$ & & $\begin{array}{l}125 \\
(3.5\end{array}$ \\
\hline
\end{tabular}




\begin{tabular}{|c|c|c|c|c|c|c|}
\hline \multicolumn{7}{|c|}{ ACCEPTED MANUSCRIPT } \\
\hline & & & & & & $\%)$ \\
\hline 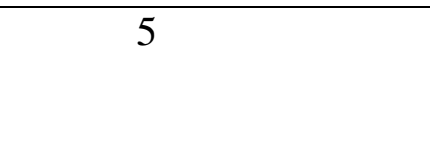 & $\begin{array}{c}12(1.3 \\
\%)\end{array}$ & $8(0.7 \%)$ & & $14(0.9 \%)$ & & $\begin{array}{c}34 \\
(1.0 \\
\%)\end{array}$ \\
\hline \multicolumn{3}{|l|}{ OCSP Classification } & \multirow{6}{*}{0.081} & & \multirow{6}{*}{$<0.001$} & \\
\hline LACI & $\begin{array}{c}337 \\
(35.4 \\
\%)\end{array}$ & $383(35.9 \%)$ & & $\begin{array}{c}458(29.5 \\
\%)\end{array}$ & & $\begin{array}{c}1,178 \\
(33.0 \\
\%)\end{array}$ \\
\hline PACI & $\begin{array}{c}326 \\
(34.2 \\
\%)\end{array}$ & $389(36.5 \%)$ & & $\begin{array}{c}619(39.8 \\
\%)\end{array}$ & & $\begin{array}{c}1,334 \\
(37.3 \\
\%)\end{array}$ \\
\hline POCI & $\begin{array}{c}155 \\
(16.3 \\
\%)\end{array}$ & $185(17.3 \%)$ & & $\begin{array}{c}276(17.7 \\
\%)\end{array}$ & & $\begin{array}{c}616 \\
(17.2 \\
\%)\end{array}$ \\
\hline TACI & $\begin{array}{c}94(9.9 \\
\%)\end{array}$ & $83(7.8 \%)$ & & $\begin{array}{c}189(12.2 \\
\%)\end{array}$ & & 366 \\
\hline Unspecified & $\begin{array}{c}41(4.3 \\
\%)\end{array}$ & $27(2.5 \%)$ & & $13(0.8 \%)$ & & $\begin{array}{l}81 \\
(2.3 \\
\%)\end{array}$ \\
\hline Prior Antiplatelet Use & $\begin{array}{c}230 \\
(24.1 \\
\%)\end{array}$ & $535(50.1 \%)$ & $<0.001$ & $566(36.4$ & $<0.001$ & $\begin{array}{c}1,331 \\
(37.2 \\
\%)\end{array}$ \\
\hline \multicolumn{7}{|l|}{ Co-Morbidities } \\
\hline $\begin{array}{l}\text { Previous } \\
\text { Stroke/Transient } \\
\text { Ischemic Attack }\end{array}$ & $\begin{array}{c}165 \\
(17.3 \\
\%)\end{array}$ & $291(27.3 \%)$ & $<0.001$ & $\begin{array}{c}309(19.9 \\
\%)\end{array}$ & 0.112 & $\begin{array}{c}765 \\
(21.4 \\
\%)\end{array}$ \\
\hline $\begin{array}{l}\text { Coronary Heart } \\
\text { Disease / } \\
\text { Myocardial } \\
\text { Infarction }\end{array}$ & $\begin{array}{c}71(7.5 \\
\%)\end{array}$ & $133(12.5 \%)$ & $<0.001$ & $\begin{array}{c}222(14.3 \\
\%)\end{array}$ & $<0.001$ & $\begin{array}{c}426 \\
(11.9 \\
\%)\end{array}$ \\
\hline $\begin{array}{l}\text { Congestive } \\
\text { Heart Failure }\end{array}$ & $23(2.4$ & $5(3.3 \%)$ & 0.244 & $58(3.7 \%)$ & 0.070 & $\begin{array}{l}116 \\
(3.2 \\
\%) \\
\end{array}$ \\
\hline Hypertension & $\begin{array}{l}150 \\
(15.7 \\
\%)\end{array}$ & $234(21.9 \%)$ & $<0.001$ & $\begin{array}{c}480(30.9 \\
\%)\end{array}$ & $<0.001$ & $\begin{array}{c}864 \\
(24.2 \\
\%)\end{array}$ \\
\hline Hyperlipidemia & $\begin{array}{c}9(0.9 \\
\%)\end{array}$ & $39(3.7 \%)$ & $<0.001$ & $92(5.9 \%)$ & $<0.001$ & $\begin{array}{l}140 \\
(3.9 \\
\%) \\
\end{array}$ \\
\hline $\begin{array}{l}\text { Diabetes } \\
\text { Mellitus }\end{array}$ & $\begin{array}{c}49(5.1 \\
\%)\end{array}$ & $74(6.9 \%)$ & 0.092 & $\begin{array}{c}167(10.7 \\
\%)\end{array}$ & $<0.001$ & $\begin{array}{l}290 \\
(8.1 \\
\%)\end{array}$ \\
\hline $\begin{array}{l}\text { Peripheral } \\
\text { Vascular } \\
\text { Disease }\end{array}$ & $\begin{array}{c}9(0.9 \\
\%)\end{array}$ & $15(1.4 \%)$ & 0.339 & $31(2.0 \%)$ & 0.042 & $\begin{array}{l}55 \\
(1.5 \\
\%) \\
\end{array}$ \\
\hline $\begin{array}{l}\text { Chronic } \\
\text { Obstructive } \\
\text { Pulmonary } \\
\text { Disease }\end{array}$ & $\begin{array}{c}23(2.4 \\
\%)\end{array}$ & $25(2.3 \%)$ & 0.917 & $61(3.9 \%)$ & 0.041 & $\begin{array}{l}109 \\
(3.0 \\
\%)\end{array}$ \\
\hline $\begin{array}{l}\text { Chronic Kidney } \\
\text { Disease }\end{array}$ & $\begin{array}{c}11(1.2 \\
\%)\end{array}$ & $12(1.1 \%)$ & 0.950 & $51(3.3 \%)$ & 0.001 & $\begin{array}{l}74 \\
(2.1 \\
\%) \\
\end{array}$ \\
\hline
\end{tabular}




\begin{tabular}{|c|c|c|c|c|c|c|}
\hline Falls & $\begin{array}{c}101 \\
(10.6\end{array}$ & $100(9.4 \%)$ & 0.358 & $183(11.8$ & 0.369 & 384 \\
& & & $\%)$ & & $\begin{array}{c}10.7 \\
\%)\end{array}$ \\
\hline Malignancy & $91(9.5$ & $86(8.1 \%)$ & 0.237 & $157(10.1$ & 0.656 & 334 \\
& $\%)$ & & & $\%)$ & & $\begin{array}{c}9.3 \\
\%)\end{array}$ \\
\hline Dementia & $\begin{array}{c}\text { 13(1.4 } \\
\%)\end{array}$ & $11(1.0 \%)$ & 0.490 & $37(2.4 \%)$ & 0.077 & 61 \\
& & & & & $\begin{array}{c}(1.7 \\
\%)\end{array}$ \\
\hline
\end{tabular}

${ }^{a}$ Clopidogrel has been compared to Aspirin

${ }^{\mathrm{b}}$ OCSP $=$ Oxford Community Stroke Project Classification, LACI = Lacunar Infarct, PACI = Partial Anterior Circulation Infarct, POCI $=$ Posterior Circulation Infarct, TACI $=$ Total Anterior Circulation Infarct. 
Table 2: Hazard Ratios of Mortality and Mortality + incident MACE (major adverse cardiovascular event) at Different Time-periods for Clopidogrel and Aspirin + Dipyridamole compared to Aspirin (Cox Proportional Hazards Model)

\begin{tabular}{|l|c|c|}
\hline & Mortality & Mortality + MACE $^{\text {a }}$ \\
\hline 0 - 90 Days & 1.00 & 1.00 \\
Aspirin & $\mathbf{0 . 6 2}(\mathbf{0 . 4 3}-\mathbf{0 . 9 1})$ & $\mathbf{0 . 7 0}(\mathbf{0 . 5 2}-\mathbf{0 . 9 4})$ \\
Aspirin + Dipyridamole & $0.97(0.59-1.59)$ & $0.90(0.60-1.36)$ \\
Clopidogrel & 1.00 & 1.00 \\
\hline $91-$ 365 Days & $0.80(0.60-1.08)$ & $0.79(0.59-1.06)$ \\
Aspirin & $0.82(0.54-1.25)$ & $0.84(0.55-1.28)$ \\
Aspirin + Dipyridamole & 1.00 & 1.00 \\
Clopidogrel & $0.98(0.76-1.27)$ & $0.95(0.73-1.24)$ \\
\hline 366 - 1095 Days & $\mathbf{0 . 3 9}(\mathbf{0 . 2 6}-\mathbf{0 . 6 0})$ & $\mathbf{0 . 5 7}(\mathbf{0 . 3 8}-\mathbf{0 . 8 5})$ \\
Aspirin & & \\
Aspirin + Dipyridamole & & \\
Clopidogrel & & \\
\hline
\end{tabular}

${ }^{\mathrm{a}} \mathrm{MACE}=$ incident stroke and/or myocardial infarction

${ }^{\mathrm{b}}$ All Cox-regression Models Adjusted For: Year Admitted, Age, Sex, Oxfordshire Community Stroke Project Classification, Pre-stroke modified Rankin score, Prior Antiplatelet Use, CoMorbidities (Previous Stroke/Transient Ischemic Attack, Myocardial Infarction/Coronary Heart Disease, Congestive Heart Failure, Hypertension, Hyperlipidemia, Diabetes Mellitus, Peripheral Vascular Disease, Chronic Obstructive Pulmonary Disease, Chronic Kidney Disease, Falls, Malignancy, Dementia) 
Table 3: Hazard Ratios of Mortality and Mortality + incident MACE (major adverse cardiovascular event) at Different Time-periods for Clopidogrel compared to Aspirin + Dipyridamole (Cox Proportional Hazards Model)

\begin{tabular}{|l|c|c|}
\hline & Mortality & Mortality + MACE $^{\text {a }}$ \\
\hline 0 - 90 Days & 1.00 & 1.00 \\
Aspirin + Dipyridamole & $\mathbf{1 . 7 7}(\mathbf{1 . 0 1}-\mathbf{3 . 1 2})$ & $1.49(0.94-2.34)$ \\
Clopidogrel & 1.00 & 1.00 \\
\hline 91 - 365 Days & $1.19(0.77-1.85)$ & $1.29(0.84-1.99)$ \\
Aspirin + Dipyridamole & 1.00 & 1.00 \\
Clopidogrel & $\mathbf{0 . 5 2}(\mathbf{0 . 3 3}-\mathbf{0 . 8 1})$ & $0.75(0.49-1.15)$ \\
\hline 366 - 1095 Days & \\
Aspirin + Dipyridamole &
\end{tabular}

${ }^{\mathrm{a}} \mathrm{MACE}=$ incident stroke and/or myocardial infarction

${ }^{\mathrm{b}}$ All Cox-regression Models Adjusted For: Year Admitted, Age, Sex, Oxfordshire Community Stroke Project Classification, Pre-stroke modified Rankin score, Prior Antiplatelet Use, CoMorbidities (Previous Stroke/Transient Ischemic Attack, Myocardial Infarction/Coronary Heart Disease, Congestive Heart Failure, Hypertension, Hyperlipidemia, Diabetes Mellitus, Peripheral Vascular Disease, Chronic Obstructive Pulmonary Disease, Chronic Kidney Disease, Falls, Malignancy, Dementia) 